\title{
Antitumor activity of Lycium barbarum polysaccharides with different molecular weights: an in vitro and in vivo study
}

\author{
Xiangliang Deng ${ }^{\mathrm{a}, \mathrm{b}}$, Xiangling Lic, Shuang Luo ${ }^{\mathrm{a}}$, Yongyan Zheng ${ }^{\mathrm{a}}$, Xia Luo and Lian Zhou ${ }^{\mathrm{a}}$ \\ aschool of Chinese Materia Medica, Guangzhou University of Chinese Medicine, Guangzhou, PR China; ${ }^{b}$ Research and Development \\ Department, Infinitus Chinese Herbal Immunity Research Centre, Guangzhou, PR, China; 'Research and Development Department, \\ Guangdong Hybribio Co. Ltd, Guangzhou, PR, China
}

\section{ABSTRACT}

The antitumor activity of Lycium barbarum polysaccharide (LBP) has been reported, but the structure-bioactivity relationship has still not been fully elucidated. In this study, four watersoluble LBP fractions with serial different molecular weights (MWs) were separated from LBP, designated LBP-2, LBP-3, LBP-4, and LBP-5. After a characteristic analysis, the relationship between MW and antitumor activity of LBP was investigated both in vitro using murine hepatoma $\mathrm{H} 22$ cells and in vivo using $\mathrm{H} 22$ tumor-bearing mice. In vitro, the results showed that all the LBP fractions had significant inhibition on $\mathrm{H} 22$ cells, in which LBP-3 had the best activity. LBP-3 could induce apoptosis, mitochondrial membrane potential destruction, and S phase arrest in $\mathrm{H} 22$ cells. In vivo, the results showed that LBP-2, LBP-3, LBP-4, and LBP-5 could inhibit the tumor growth in $\mathrm{H} 22$ tumor-bearing mice by $18.18 \%, 37.97 \%, 9.09 \%$, and $14.44 \%$, respectively. However, only LBP3 was able to decrease the tumor weight significantly in $\mathrm{H} 22$ tumor-bearing mice. Meanwhile, all the LBP fractions did not show significant toxicity to murine splenocytes, thymus, and spleen. Taken together, these results demonstrated that the antitumor activity of LBP was closely related to its MW, and LBP-3 with medium MW (40-350 kDa) was the main active fraction.

\section{ARTICLE HISTORY}

Received 18 May 2017

Accepted 30 October 2017

\section{KEYWORDS}

Lycium barbarum

polysaccharide; molecular weight; antitumor activity; H22 cells; flow cytometry; apoptosis

\section{Introduction}

Lycium barbarum polysaccharide (LBP), which is extracted from the fruit of a well-known Chinese herb Lycium barbarum, is found to have antitumor activity in recent years. In vitro study results showed that LBP treatment inhibited tumor cells growth. Zhang [1] found that LBP treatment inhibited the growth of QGY7703 cells via induction of Sphase cell-cycle arrest and calcium-related apoptosis. Similar studies showed that LBP treatment could inhibit the growth of mouse colon cancer cells, human gastric cancer MGC-803, and SGC-7901 cells, and arrest the cell cycles at the $\mathrm{G} 0 / \mathrm{G} 1$ or $S$ phases $[2,3]$. The anticancer effects of LBP were also demonstrated in tumor-bearing mice. Gan [4] revealed that a polysaccharide-protein complex from Lycium barbarum could significantly inhibit the growth of transplantable sarcoma S180 and improved the immune system in S180-bearing mice. Another study led by Zhang [5] found that LBP could obviously depress the death rate of $\mathrm{H} 22$ tumor-bearing mice and diminish gross tumor volume and weight.

Although the anticancer effect of LBP has been demonstrated both in vitro and in vivo, various LBP samples, obtained by different methods, have different structures and molecular weight (MW) [6]. Recent studies have indicated that biological activities of the polysaccharide partly depend on its MW [7]. LBP has an MW range of $10-2300 \mathrm{kDa}$, and its antitumor activity is probably related to MW [7]. Zhang [8] observed the effects of LBP fractions on human liver cancer cells (SMMC-7721) and found that LBP-a4 with an MW of $10.2 \mathrm{kDa}$ could inhibit the proliferation of SMMC-7721 cells in a dose- and time-dependent manner, but LBP-p8 with an MW of $6.50 \times 10^{3} \mathrm{kDa}$ could promote the growth of SMMC-7721 cells. However, the detailed relationship between the MWs and antitumor activities of LBP fractions is still not fully clear.

To further study the MW-antitumor activity relationship of LBP, LBP was separated into five fractions (LBP-1, LBP-2, LBP-3, LBP-4, and LBP-5) with serial different MWs by ultrafiltration membranes in this study. Then, the water-soluble LBP fractions (LBP-2, LBP-3, LBP-4, and LBP-5) were taken to investigate the antitumor activity both using murine hepatoma $\mathrm{H} 22$ cells in vitro and using H22 tumor-bearing mice in vivo.

CONTACT Lian Zhou zl@gzucm.edu.cn @ Guangzhou University of Chinese Medicine, No. 232 Wai Huan Dong Road, Guangzhou Higher Education Mega Center, Guangzhou 51006, PR China

(4) Supplemental data for this article can be accessed here.

(c) 2017 The Author(s). Published by Informa UK Limited, trading as Taylor \& Francis Group.

This is an Open Access article distributed under the terms of the Creative Commons Attribution License (http://creativecommons.org/licenses/by/4.0/), which permits unrestricted use, distribution, and reproduction in any medium, provided the original work is properly cited. 


\section{Materials and methods}

\section{Materials}

Penicillin-Streptomycin solution was purchased from Genom Biomedical Technology Co., Ltd (Hangzhou, China). Cisplatin Injection was purchased from Nanjing Pharmaceutical Factory Co.,Ltd (Nanjing, China). Doxorubicin (Dox) for injection was purchased from Shenzhen Main Luck Pharmaceuticals Inc. (Shenzhen, China). Dimethyl sulfoxide (DMSO) was purchased from Tianjin Yongda Chemiacl Reagent Co., Ltd (Tianjin, China). Cyclophosphamide (Cy) for injection was purchased from Shanxi Powerdone Pharmaceutics Co., Ltd (Shanxi, China). RPMI-1640 was purchased from Corning; Rhodamine 123, propidium iodide (PI), 3-(4,5-dimethylthiazol-2-yl)-2,5-diphenyltetrazolium bromide (MTT), carbazole, galacturonic acid, and ribonuclease (RNase) were purchased from Sigma (St. Louis, USA). Annexin V-FITC/PI Apoptosis Detection Kit was purchased from eBioscience (Santa Clara, USA). Fetal bovine serum (FBS) was purchased from Biological Industries (Kibbutz Beit-Haemek, Israel).

\section{Preparation and characterization analysis of LBP fractions}

LBP was prepared with hot water as described previously [9]. The LBP fractions with different series MW were prepared according to the relevant reference [8]. Briefly, the LBP fractions were isolated by ultrafiltration membranes with an MW cutoff (MWCO) of 3, 8, 40, 350, and $400 \mathrm{kDa}$ successively. Based on the MW, the fractions were named LBP-1, LBP-2, LBP-3, LBP-4, and LBP-5, respectively. The powder of the fractions was obtained by freeze-drying. The water-soluble LBP fractions (LBP-2, LBP-3, LBP-4, and LBP-5) were taken for investigation in the following experiments.

The characterization of LBP fractions was analyzed as described previously [10-13]. Briefly, the total sugar was determined by the phenol-sulfuric acid method [10]. Protein content was measured by the Bradford method [11]. Uronic acid was measured by the sulfuric acid carbazole colorimetry method, and galacturonic acid was used as the standard [12]. The vibrations of molecules and polar bonds between the different atoms in LBP fractions were analyzed using IR (Avatar 30FTIR infrared spectrometer, Nicnet) [13].

\section{Cell line and animals}

Murine hepatoma H22 cells were cultured in RMPI1640 with $10 \% \mathrm{FBS}, 100 \mathrm{U} / \mathrm{mL}$ penicillin, and $100 \mu \mathrm{g} /$ $\mathrm{mL}$ streptomycin at $37^{\circ}$ with $5 \% \mathrm{CO}_{2}$. The cells were subcultured until they reached the logarithmic growth phase.

Specific pathogen-free male $\mathrm{BALB} / \mathrm{c}$ mice, weighing $20 \pm 2 \mathrm{~g}$, were purchased from the Guangdong Medical Laboratory Animal Center (Foshan, China). Animals were fed on a standard laboratory diet and water, and were kept in environmentally controlled quarters with temperature maintained at $25^{\circ} \mathrm{C}$ and a $12 / 12 \mathrm{~h}$ dark/ light cycle. All experimental procedures were approved by the Animal Care and Use Committee of Guangzhou University of Chinese Medicine, PR China.

\section{In vitro antitumor assay}

\section{Cell viability assay}

The effect of LBP fractions on cell viability was measured using the MTT assay. H22 cells in logarithmic growth phase were plated in 96-well plates $\left(1 \times 10^{4}\right.$ cells/well $)$ and treated with LBP-2, LBP-3, LBP-4, and LBP-5 (400, 800, 1200 , and $1600 \mu \mathrm{g} / \mathrm{mL}$ ) immediately for $24 \mathrm{~h}$ and $48 \mathrm{~h}$. MTT ( $5 \mathrm{mg} / \mathrm{mL}$ ) was added to each well at $24 \mathrm{~h}$ and $48 \mathrm{~h}$ respectively, and cells were incubated for another $4 \mathrm{~h}$. After centrifugation at $300 \times g$ for $10 \mathrm{~min}$, the supernatant was removed, and $0.15 \mathrm{~mL}$ of DMSO was added to each well. The absorbance at 570 and $630 \mathrm{~nm}$ was measured on a microplate reader (Thermo Fisher Scientific, Waltham, USA). The percent viability of the treated cells was calculated using the following equation: relative viability $(\%)=\left(A_{570 \mathrm{~nm}}-A_{630 \mathrm{~nm}}\right)$ sample $/\left(A_{570 \mathrm{~nm}}-A_{630 \mathrm{~nm}}\right)$ control $\times 100 \%$.

In order to determine whether LBP fractions also have cytotoxicity to immune cells, the effects of LBP fractions on splenocytes viability were investigated in this study. Splenocytes were prepared as described previously with minor modifications [14]. Briefly, splenocytes were isolated from $\mathrm{BALB} / \mathrm{c}$ mice, and the erythrocytes were lysed with red blood cell lysis buffer (0.829 $\mathrm{mg} / \mathrm{mL} \mathrm{NH} \mathrm{NH}_{4} \mathrm{Cl}, 0.037 \mathrm{mg} / \mathrm{mL} \mathrm{Na} \mathrm{Na}_{2}$ ETA and $0.100 \mathrm{mg} / \mathrm{mL} \mathrm{KHCO}_{3}$ ). After washing twice with precold phosphate-balanced solution (PBS), cells were resuspended in RMPI-1640 with $10 \%$ FBS, $100 \mathrm{U} / \mathrm{mL}$ penicillin, and $100 \mu \mathrm{g} / \mathrm{mL}$ streptomycin, and seeded in 96-well plates $\left(4 \times 10^{5}\right.$ cells/well, sextuplicate wells in each group). After being treated with LBP fractions (400, 800,1200 , and $1600 \mu \mathrm{g} / \mathrm{mL}$ ) for $72 \mathrm{~h}$, the cell viability was measured by MTT assay as described above.

\section{Cell-proliferation assay}

The effect of LBP fractions on cell proliferation was detected by flow cytometry (FACSCanto II flow cytometer, BD Biosciences, Franklin Lakes, USA). H22 cells were treated with LBP-2, LBP-3, LBP-4, and LBP-5 $(400,800,1200$, and $1600 \mu \mathrm{g} / \mathrm{mL})$ for 24,48 , 
and $72 \mathrm{~h}$. Cells treated with RPMI-1640 medium were taken as negative controls, and those treated with cisplatin $(10 \mu \mathrm{g} / \mathrm{mL})$ were taken as positive controls. The cells were collected and washed twice with PBS before detection. Relative cell number was counted by flow cytometry for 1 min under a medium speed. The inhibition of LBP fractions on proliferation of $\mathrm{H} 22$ cells was calculated using the following equation: inhibition rate $(\%)=($ cell number of negative control - cell number of sample) / cell number of negative control $\times 100 \%$.

\section{Apoptosis analysis}

Cell apoptosis was analyzed using the Annexin V-FITC/PI apoptosis detection kit as described previously [15]. Briefly, after being treated with LBP-3 $(400,800,1200 \mu \mathrm{g} / \mathrm{mL})$ for $48 \mathrm{~h}, \mathrm{H} 22$ cells were harvested and washed twice with $\mathrm{PBS}$ and stained with Annexin V-FITC/PI according to the manufacturer's instructions. The samples were detected on an FACS Canto II flow cytometer (BD Biosciences) and analyzed using FACS Diva ${ }^{\text {tw }}$ software.

\section{MMP measurement}

The MMP was detected by Rhodamine123 (Rho123), using flow cytometry and a fluorescence microscope (Nikon). After being treated with LBP-3 (400, 800, $1200 \mu \mathrm{g} / \mathrm{mL}$ ) for $48 \mathrm{~h}, \mathrm{H} 22$ cells were washed with PBS and dyed with Rho123 $(10 \mu \mathrm{g} / \mathrm{mL})$ at $37^{\circ} \mathrm{C}$ for $30 \mathrm{~min}$. Morphological observations were carried out using a fluorescence microscope. The fluorescence intensity of cell was detected on an FACS Canto II flow cytometer (BD Biosciences) and analyzed with FACS Diva ${ }^{\mathrm{m}}$ software.

\section{Cell-cycle analysis}

Cell cycles were analyzed by flow cytometry with PI staining as described previously [1]. Briefly, H22 cells were seeded in 24 -well plates $\left(5 \times 10^{4}\right.$ cells/well $)$ and treated with LBP-3 $(400,800,1200 \mu \mathrm{g} / \mathrm{mL})$ for $72 \mathrm{~h}$. The cells were harvested, washed twice with PBS, and fixed with $70 \%$ ethanol for $24 \mathrm{~h}$ at $-20^{\circ} \mathrm{C}$. After two washes with PBS, cells were stained with PI $(10 \mu \mathrm{g} / \mathrm{mL})$ and RNase $(10 \mu \mathrm{g} / \mathrm{mL})$ at room temperature for $30 \mathrm{~min}$ in the dark. The samples were detected by flow cytometry and analyzed with ModFit LT cell-cycle-analysis software.

\section{In vivo antitumor assay}

\section{Animal experiments and treatment protocol}

To investigate the antitumor activity of LBP fractions in vivo, the murine $\mathrm{H} 22$ hepatocarcinoma model was used in this study. The animal experiments and treatment protocol were prepared as described previously with minor modifications [16]. Briefly, H22 cells $\left(2 \times 10^{6}\right.$ cells/mouse) were injected into the right armpit subcutaneously in BALB/c mice. Twenty-four hours after the tumor inoculation of $\mathrm{H} 22$ cells, the mice were divided into the model group, LBP-2 group, LBP-3 group, LBP-4 group, and LBP-5 group. Mice were treated with LBP fractions intragastrically at a dose of $250 \mathrm{mg} / \mathrm{kg}$, except for the model group. The treatments were administered once daily for 10 days. To further investigate whether LBP-3 could inhibit tumor growth in a dose-dependent manner, mice were divided into the model group, cyclophosphamide (Cy, $20 \mathrm{mg} / \mathrm{kg}$ ) treatment group, Doxorubicin (Dox, $10 \mathrm{mg} / \mathrm{kg}$ ) treatment group, and three doses of LBP-3 $(62.5,125$ and $250 \mathrm{mg} / \mathrm{kg})$ treatment group. Cy was given intragastrically once daily for 10 days. Dox was injected intraperitoneally on day 1 . LBP-3 was given intragastrically as described above.

\section{Tumor inhibition rate and immune organ index}

Twenty-four hours after the last administration, mice were killed immediately by cervical dislocation after anesthesia with chloral hydrate. The tumor, spleen, and thymus were immediately dissected and weighed. The tumor inhibition rate and immune organ indexes were calculated using the following equation respectively: tumor inhibition rate $(\%)=$ (the average tumor weight of model group - the average tumor weight of LBP fraction group) / the average tumor weight of model group $\times 100 \%$, spleen or thymus index $(\mathrm{mg} / \mathrm{g})=$ the weight of spleen or thymus (mg) / body weight (g).

\section{Statistical analysis}

All values were expressed as mean $\pm \mathrm{SD}$. A one-way analysis of variance, followed by the Dunnett $t$ test, was used to assess the statistical significance of differences between experimental groups. A $P$ value of $<0.05$ was considered to be significant.

\section{Results}

\section{Characterization of LBP fractions}

The results showed that the total sugar contents of LBP-2, LBP-3, LBP-4, and LBP-5 were $66.88 \%$, $54.47 \%, 56.53 \%$, and $55.21 \%$, respectively. The uronic acid, protein, and bound water were also found in the LBP fractions (Table 1).

The carbohydrate-related molecules, such as $\mathrm{C}-\mathrm{H}$ and $\mathrm{C}=\mathrm{C}$ bonds, $\mathrm{CH}_{3}$ group, and glycosidic linkages, have characteristic absorptions in IR spectra [13]. Thus, IR spectra are usually used to identify the 
Table 1. Components of LBP fractions.

\begin{tabular}{lccrc}
\hline Fractions & LBP-2 & LBP-3 & LBP-4 & LBP-5 \\
\hline Molecular weights (kDa) & $350-400$ & $40-350$ & $8-40$ & $3-8$ \\
Total sugar (\%) & 66.88 & 54.7 & 56.53 & 55.21 \\
Uronic acid (\%) & 11.03 & 8.11 & 10.65 & 10.14 \\
Protein (\%) & 0.27 & 1.14 & 0.11 & 0.34 \\
Bound water (\%) & 12.80 & 14.59 & 14.88 & 15.85 \\
Fat (\%) & 4.30 & 11.10 & 7.25 & 2.10 \\
\hline
\end{tabular}

characteristic absorptions of polysaccharides. In the present study, the results showed that the IR spectra in all the LBP fractions appeared at about 3400, 2930, $1627,1410,1077,918,865,818$, and $778 \mathrm{~cm}^{-1}$ (Table 2). However, the absorption at $918 \mathrm{~cm}^{-1}$ was mainly found in LBP-4. The absorption peaks at about 3400 and $2930 \mathrm{~cm}^{-1}$ were due to hydroxyl stretching vibrations and $\mathrm{C}-\mathrm{H}$ stretching vibrations, respectively $[17,18]$. The signal at about $1627 \mathrm{~cm}^{-1}$ was due to the bound water [17], consistent with the fact that the bound water was found in the LBP fractions. The absorption at 1410 and $1077 \mathrm{~cm}^{-1}$ was possibly due to nonsymmetric $\mathrm{CH}_{3}$ bending and $\mathrm{C}-\mathrm{O}$ stretching vibration, respectively [13]. The small absorption band at $918 \mathrm{~cm}^{-1}$ was characteristic of $\beta$-glycosidic linkages between the sugars [18] and indicated that the $\beta$-glycosidic linkage mainly existed in the LBP- 4 . The characteristic absorption bands at $865 \mathrm{~cm}^{-1}$ and $818 \mathrm{~cm}^{-1}$ indicated that $\alpha$-configuration and mannose existed in the LBP fractions $[17,19]$. The present results demonstrated that all the LBP fractions shared most of the characteristic absorptions.

\section{LBP fractions were toxic to $\mathrm{H} 22$ cells, but not to murine splenocytes}

To investigate the effect of the water-soluble LBP fractions (LBP-2, LBP-3, LBP-4, and LBP-5) on the viability of $\mathrm{H} 22$ cells, cells were measured by MTT assay after being treated with LBP fractions for $24 \mathrm{~h}$ and $48 \mathrm{~h}$. The results showed that all the LBP fractions inhibited the viability of $\mathrm{H} 22$ cells in a dose-dependent manner (Figure 1(a,b)). Among these fractions, LBP-3 had the best inhibition with the lowest cell viability at the dose of $1600 \mu \mathrm{g} / \mathrm{mL}$ for $48 \mathrm{~h}$.

To further confirm whether LBP fractions were also toxic to normal cells, the viability of murine splenocytes was measured by MTT assay after being treated

Table 2. Results of IR analysis of LBP fractions.

\begin{tabular}{ll}
\hline Fractions & \multicolumn{1}{c}{ IR bands $\left(\mathrm{cm}^{-1}\right)$} \\
\hline LBP-2 & $3429,2931,1634,1410,1077,865,818,778$ \\
LBP-3 & $3405,2932,1627,1410,1077,866,818,778$ \\
LBP-4 & $3403,2933,1625,1412,1077,918,865,818,778$ \\
LBP-5 & $3411,2932,1625,1412,1077,865,818,778$ \\
\hline
\end{tabular}

with LBP fractions for $48 \mathrm{~h}$. As shown in Figure 1(c), the results showed that LBP fractions were not toxic to murine splenocytes. On the contrary, LBP-3, LBP-4, and LBP-5 enhanced the cell viability. This was consistent with the previous studies that LBP could promote the proliferation of murine lymphocytes [20].

\section{LBP fractions inhibited the growth of $\mathrm{H} 22$ cells, and LBP-3 had the highest inhibition activity}

The effect of LBP fractions on H22 cells proliferation were measured by FCM. The results (Figure 2(a)) showed that all the LBP fractions could inhibit the growth of $\mathrm{H} 22$ cells in a dose-dependent manner. Among the four fractions, LBP-3 had the highest inhibition activity, especially at the dose of $1600 \mu \mathrm{g} / \mathrm{mL}$ for $48 \mathrm{~h}$ where the percentage of inhibition was over $60 \%$. Further study showed that LBP-3 inhibited growth of $\mathrm{H} 22$ cells in dose- and timedependent manners (Figure 2(b)).

Since LBP-3 had the highest inhibition activity on $\mathrm{H} 22$ cells, the following in vitro experiments were focused on LBP-3.

\section{LBP-3 induced apoptosis of H22 cells}

Annexin V-FITC/PI apoptosis detection kit is a standard method that is used to assess cell apoptosis [21]. A previous study showed that LBP could induce apoptosis of human hepatoma SMMC-7721 cells [6]. To determine whether LBP-3 could induce apoptosis of H22 cells, the apoptosis of cells was measured using the Annexin V-FITC/PI apoptosis detection kit using FCM after the cells were treated with LBP-3 for $24 \mathrm{~h}$ and $48 \mathrm{~h}$ (Figure 3 ). The results showed that LBP-3 significantly induced apoptosis of $\mathrm{H} 22$ cells in a dose-dependent manner.

\section{LBP-3 disrupted MMP on H22 cells}

Since the mitochondrion is the powerhouse of the cell [22], disruption of the mitochondrial membrane potential (MMP) is one of the crucial factors in cell apoptosis [23] and has become a pharmacological target in cancer therapy for alterations in mitochondrial structure and functions that have long been observed in cancer cells [24]. Rhodamine-123 as a cationic fluorescent probe has been used for the measurement of MMP [25]. To investigate whether LBP-3-induced apoptosis of $\mathrm{H} 22$ cells was related to the MMP disruption, H22 cells were treated with different concentrations of LBP-3 for $48 \mathrm{~h}$. Then, the MMP was measured using Rho123 as a fluorescent probe with fluorescence microscopy and FCM, respectively. The fluorescence microscopy results showed that Rho123 accumulation 

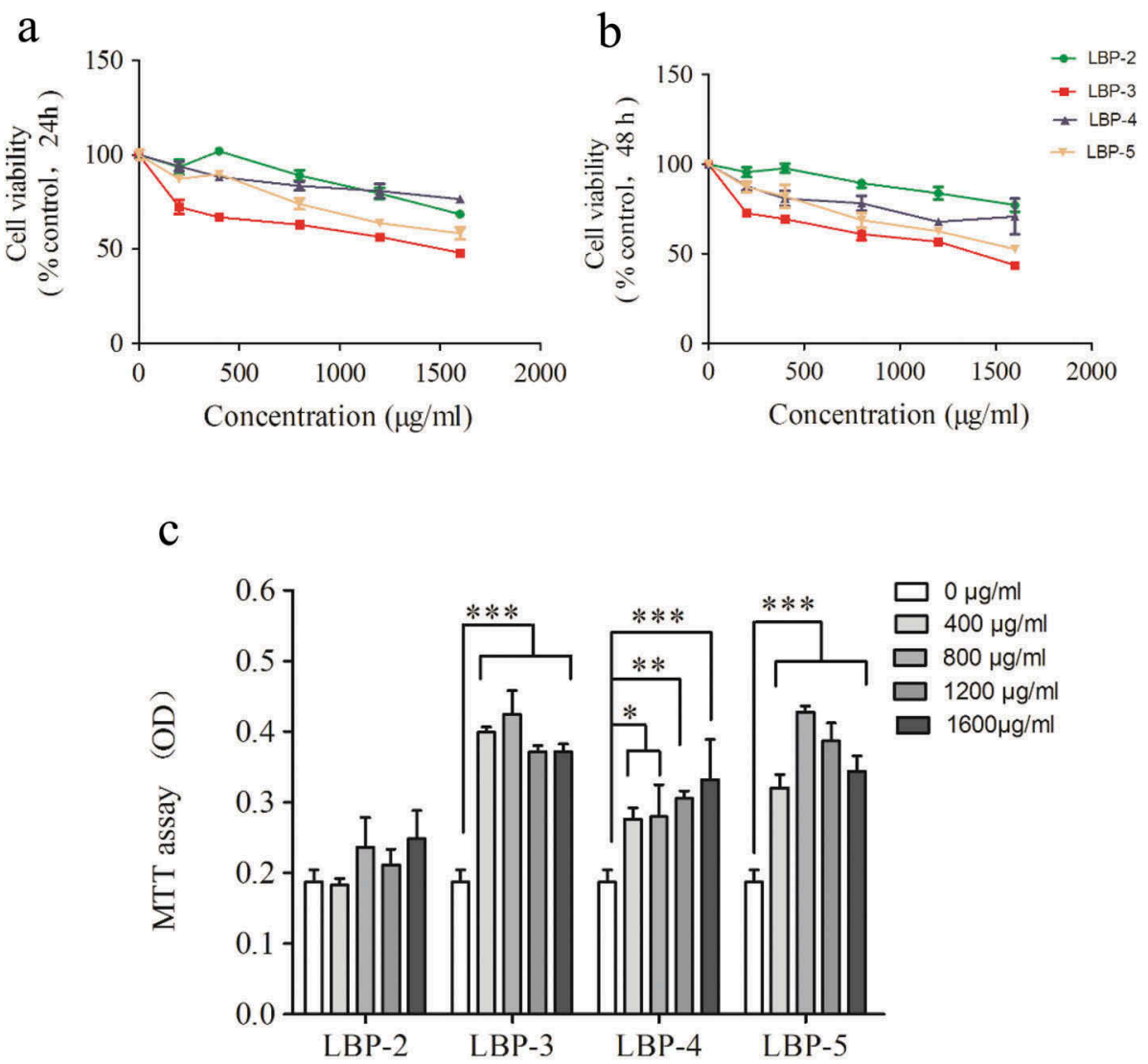

Figure 1. Effect of LBP fractions on the viability of $\mathrm{H} 22$ cells and splenocytes. $\mathrm{H} 22$ cells were treated with LBP fractions for $24 \mathrm{~h}$ (A) and $48 \mathrm{~h}$ (B). Splenocytes were treated with LBP fractions for $48 \mathrm{~h}$ (C). Cell viability was measured by MTT assay, and results are presented as percentage of control (untreated cells). Values are shown as the means \pm SD of three replicates $(n=3)$ for H22 cells or six replicates $(n=6)$ for splenocytes. ${ }^{*} P<0.05,{ }^{*} P<0.01$ and ${ }^{* * *} P<0.001$, compared with the control group $(0 \mu \mathrm{g} / \mathrm{mL})$.
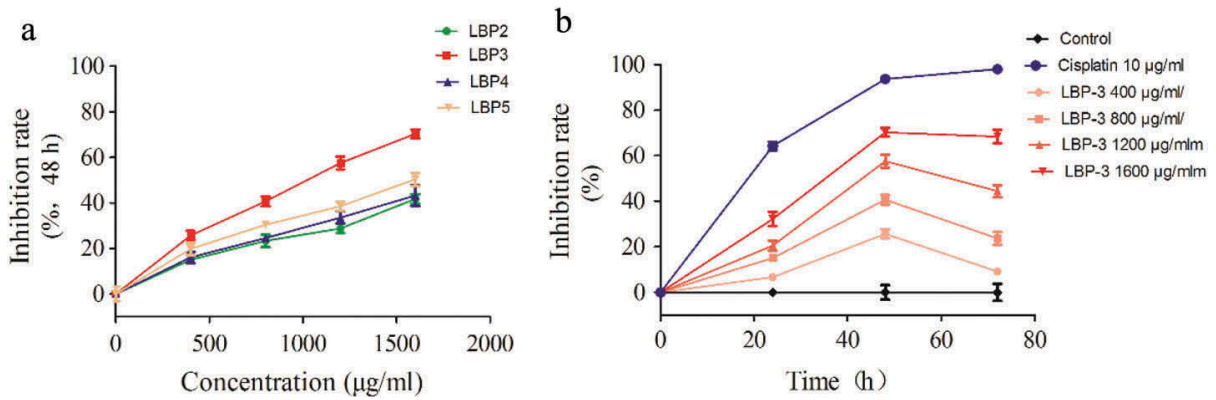

Figure 2. Effect of LBP fractions on $\mathrm{H} 22$ cells proliferation. (A) Cells were treated with LBP2-5 (400-1600 $\mu \mathrm{g} / \mathrm{mL})$ for $48 \mathrm{~h}$. (B) Cells were treated with LBP-3 $(400-1600 \mu \mathrm{g} / \mathrm{mL})$ for $24-72 \mathrm{~h}$. Cell numbers were counted by FCM, and results are presented as a percentage of control (untreated cells). Values are shown as the Means \pm SD of three replicates $(n=3)$.

in $\mathrm{H} 22$ cells decreased significantly after treatment with LBP-3 (Figure 4(a)). The FCM analysis results showed that LBP-3 disrupted the MMP of H22 cells in a dosedependent manner (Figure 4(b)).

\section{LBP-3 arrested H22 cells at the S phase}

Previous studies had shown that LBP could arrest different human cancer cell lines at different phases
[1-3]. To investigate whether LBP-3 inhibited H22 cell proliferation was related to arrest of cell-cycle progression, cell-cycle distribution of $\mathrm{H} 22$ cells was assayed by FCM after being treated with LBP-3 $(400,800$, and $1200 \mu \mathrm{g} / \mathrm{mL})$ for $72 \mathrm{~h}$. The results showed that LBP-3 treatment caused a significant increase in cell number in the $S$ phase (Table 3 and Figure 5), suggesting that LBP-3 could arrest H22 cells at the $S$ phase directly. 


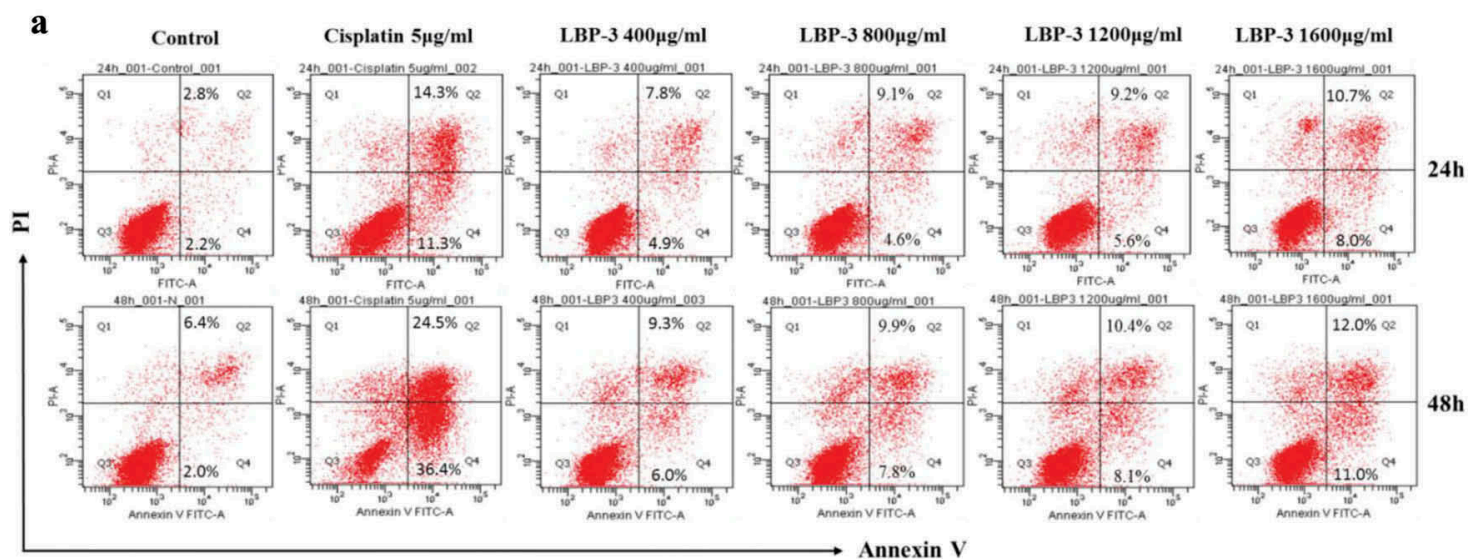

b
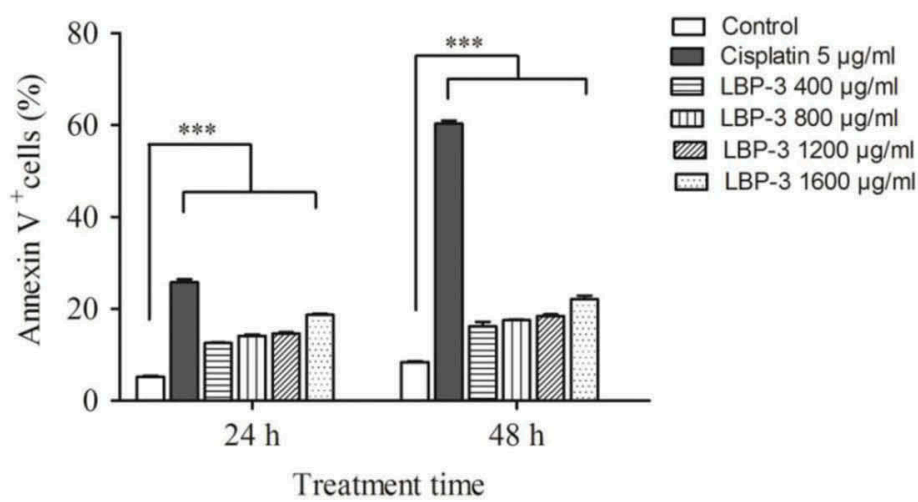

Figure 3. Effect of LBP-3 on H22 cells apoptosis. Cells were treated with LBP-3 (400-1600 $\mu \mathrm{g} / \mathrm{mL})$ for 24 and $48 \mathrm{~h}$. Cells were stained by Annexin V/PI, and the apoptotic cell death (Annexin $\mathrm{V}+$ ) was analyzed by FCM. Values are shown as the means \pm SD of three replicates $(n=3)$. ${ }^{* *} P<0.001$, compared with the control group.

a
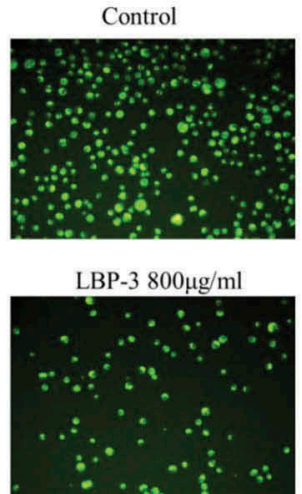

LBP-3 $400 \mu \mathrm{g} / \mathrm{ml}$

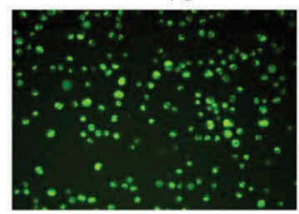

LBP-3 $1200 \mu \mathrm{g} / \mathrm{ml}$

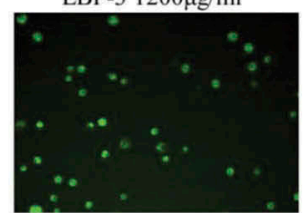

b

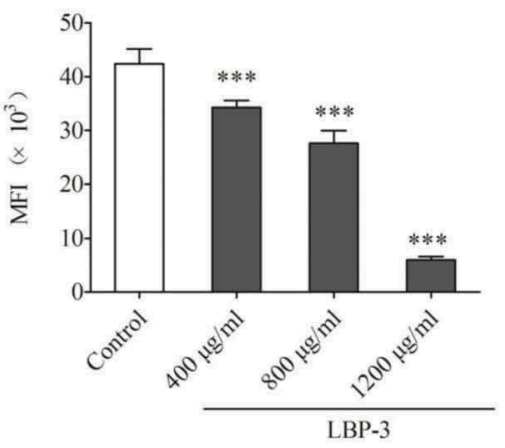

Figure 4. Effect of LBP-3 on H22 cells MMP. After being treated with LBP-3 (400-1200 $\mu \mathrm{g} / \mathrm{mL})$ for $48 \mathrm{~h}$, cells were stained with Rho123 and observed in fluorescence microscopy with $\times 200$ magnification (A). The Rho123 MFI of cells was measured by flow cytometry (B). Results of MMP are presented as mean of Rho123 MFI. Values were shown as the means \pm SD of three replicates $(n=3) .{ }^{* * *} P<0.001$, compared with the control group.

Effects of LBP fractions on tumor growth, thymus, and spleen index in $\mathrm{H} 22$ tumor-bearing mice

In order to confirm the results that LBP-3 had the highest antitumor activity as shown above among the
LBP fractions, the effects of LBP fractions on tumor growth in $\mathrm{H} 22$ tumor-bearing mice were investigated. Since tumor-mass reduction often indicates a strong antitumor effect [16], tumor inhibition rate as an indicator was used to evaluate the antitumor activity of 

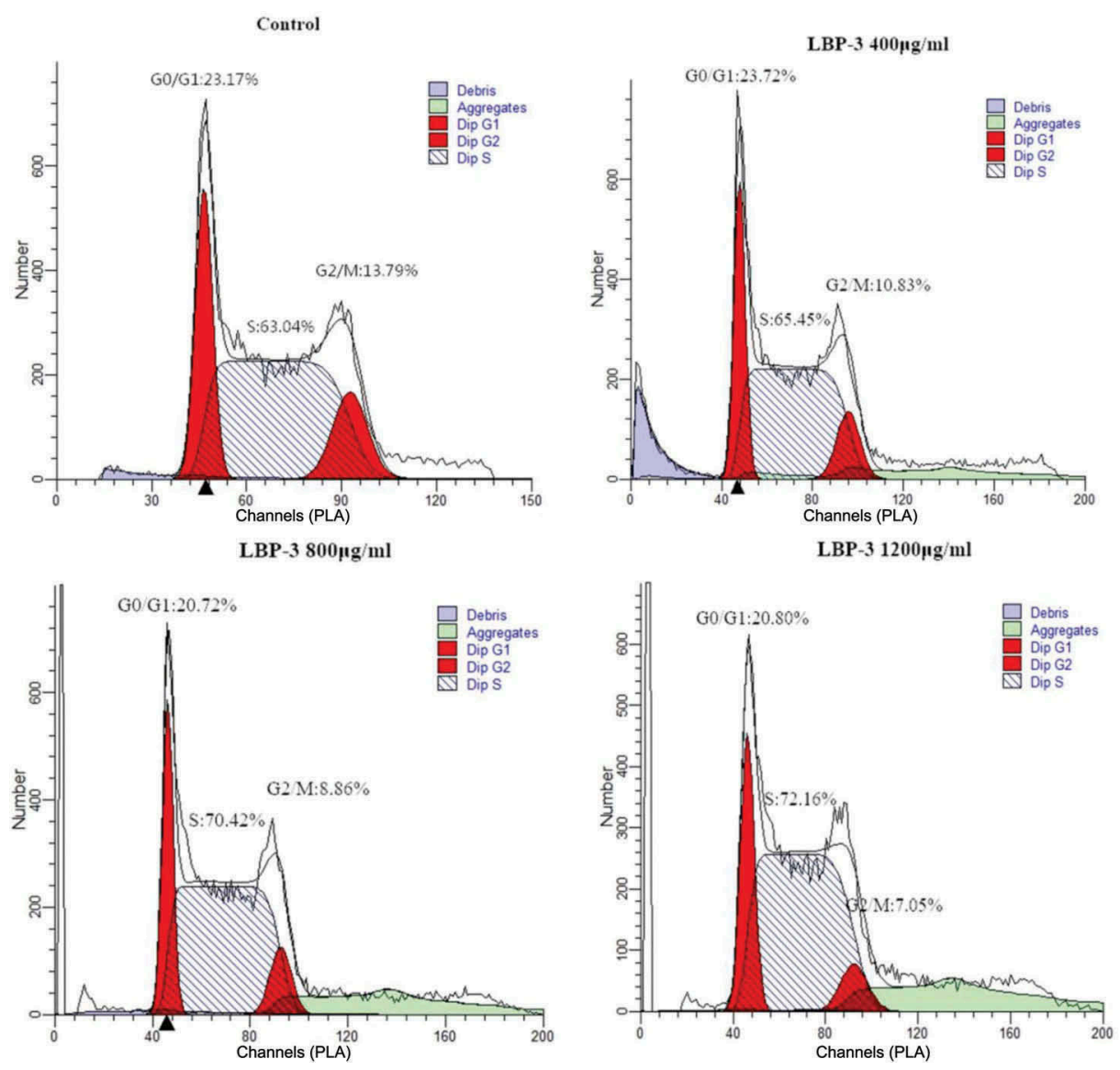

Figure 5. Inhibition of cell-cycle progress in H22 cells by treatment with LBP-3. H22 cells were treated with LBP-3 or medium for $72 \mathrm{~h}$. Cells were fixed with $70 \%$ ethanol and stained with PI, and then the cell-cycle distribution was analyzed by flow cytometry.

Table 3. Effect of LBP-3 on cell-cycle progression in H22 cells.

\begin{tabular}{lcccc}
\hline Groups & Concentration $(\mu \mathrm{g} / \mathrm{mL})$ & $\mathrm{G})$ & S phase $(\%)$ & $\mathrm{G}$ ) \\
\hline Control & 0 & $23.83 \pm 0.58$ & $63.7 \pm 0.96$ & $12.48 \pm 1.32$ \\
LBP-3 & 400 & $23.82 \pm 0.09$ & $65.86 \pm 1.07^{*}$ & $10.59 \pm 0.67$ \\
& 800 & $21.49 \pm 0.46^{* * *}$ & $70.41 \pm 0.72^{* * *}$ & $8.03 \pm 0.82^{* * *}$ \\
& 1200 & $21.17 \pm 0.37^{* * *}$ & $72.25 \pm 0.1^{* * *}$ & $6.58 \pm 0.47^{* * *}$ \\
\hline
\end{tabular}

Data are shown as mean $\pm \mathrm{SD}(n=3) .{ }^{*} P<0.05,{ }^{* *} P<0.01,{ }^{* *} P<0.001$ vs the control group.

LBP fractions in the present study. The results showed that LBP-2, LBP-3, LBP-4, and LBP-5 could inhibit tumor growth in $\mathrm{H} 22$ tumor-bearing mice by $18.18 \%$, $37.97 \%, 9.09 \%$, and $14.44 \%$, respectively. However, only LBP-3 significantly decreased the tumor weight in the mice (Table 4). In the further study, we found that LBP-3 inhibited the tumor growth in a dosedependent manner (Table 5).

Accumulating evidence had demonstrated that chemotherapy drugs often resulted in immunosuppressive side-effects [26-30]. To investigate whether LBP fractions could cause immunosuppressive side-effects in H22 tumor-bearing mice, the effects of LBP fractions on the spleen and thymus index were investigated in the present study. As expected, Dox and Cy significantly reduced the thymus index of the mice (Table 5).
However, the LBP fractions had no significant effect on the spleen and thymus index of the mice (Tables 4 and $5)$. The results indicated that the LBP fraction did not cause immunosuppressive side-effects in the H22 tumor-bearing mice.

\section{Discussion}

In the present study, four water-soluble LBP fractions with serial different MW were isolated from LBP, in which we found that LBP-3 with medium MW had the highest antitumor activity in both in vitro and in vivo studies.

Biological activities of the polysaccharide partly depend on its MW [7]. Polysacchrides from Lycium barbarum have been demonstrated to have anticancer activity both in vitro and in vivo. However, LBP has an MW range of 
Table 4. Effect of LBP fractions on tumor growth, thymus index, and spleen index in $\mathrm{H} 22$ tumor-bearing mice.

\begin{tabular}{lccccc}
\hline Groups & Dose $(\mathrm{mg} / \mathrm{kg})$ & Tumor weight $(\mathrm{g})$ & Inhibition rate $(\%)$ & Spleen index $(\mathrm{mg} / \mathrm{g})$ & Thymus index $(\mathrm{mg} / \mathrm{g})$ \\
\hline Model & 0 & $1.87 \pm 0.65$ & - & $7.08 \pm 1.05$ & $1.32 \pm 0.39$ \\
LBP-2 & 250 & $1.53 \pm 0.37$ & 18.18 & $6.66 \pm 1.59$ & $1.35 \pm 0.33$ \\
LBP-3 & 250 & $1.16 \pm 0.40^{*}$ & 37.97 & $7.25 \pm 1.81$ & $1.44 \pm 0.29$ \\
LBP-4 & 250 & $1.70 \pm 0.43$ & 9.09 & $7.99 \pm 0.43$ & $1.52 \pm 0.34$ \\
LBP-5 & 250 & $1.60 \pm 0.72$ & 14.44 & $7.33 \pm 1.17$ & $1.41 \pm 0.34$ \\
\hline
\end{tabular}

Data are shown as mean \pm SD $(n=10) .{ }^{*} P<0.05$ vs the model group.

Table 5. Effect of LBP-3 on tumor growth and thymus index in $\mathrm{H} 22$ tumor-bearing mice.

\begin{tabular}{lcccc}
\hline Groups & $\begin{array}{c}\text { Dose }(\mathrm{mg} / \\
\mathrm{kg})\end{array}$ & $\begin{array}{c}\text { Tumor weight } \\
(\mathrm{g})\end{array}$ & $\begin{array}{c}\text { Inhibition rate } \\
(\%)\end{array}$ & $\begin{array}{c}\text { Thymus index } \\
(\mathrm{mg} / \mathrm{g})\end{array}$ \\
\hline Model & & $1.63 \pm 0.54$ & - & $1.05 \pm 0.27$ \\
Cy & 20 & $0.86 \pm 0.25^{* *}$ & 47.24 & $0.38 \pm 0.11^{* * *}$ \\
Dox & 10 & $0.24 \pm 0.09^{* * *}$ & 85.28 & $0.15 \pm 0.06^{* * * *}$ \\
LBP-3 & 62.5 & $1.23 \pm 0.35$ & 24.54 & $1.04 \pm 0.19$ \\
& 125 & $1.15 \pm 0.51$ & 29.45 & $1.16 \pm 0.21$ \\
& 250 & $0.90 \pm 0.40^{* *}$ & 44.79 & $1.13 \pm 0.30$ \\
\hline
\end{tabular}

Data are shown as mean \pm SD $(n=8) .{ }^{* *} P<0.01,{ }^{* *} P<0.001$ vs the control group.

$10-2300 \mathrm{kDa}$ [7], and the detailed relationship between the MW and antitumor activities of LBP fractions is still unclear. To clarify this, LBP were cut into five fractions with a series of different MWs, and the four water-soluble fractions were taken for investigation in the present study. Firstly, we investigated the effects of LBP fractions on viability and proliferation of $\mathrm{H} 22$ cells in vitro. Although all the LBP fractions could inhibit the viability and proliferation of $\mathrm{H} 22$ cells, LBP-3 had shown the best activity. Secondly, we investigated the effect of LBP fractions on tumor growth in $\mathrm{H} 22$ tumor-bearing mice to confirm the in vitro results. In accordance with the study in vitro, LBP3 had the best antitumor activity among the four LBP fractions in vivo. To our knowledge, this is the first investigation of antitumor activity in an LBP fraction with a series of different MWs both in vitro and in vivo at the same time. The results indicate that LBP-3 is the main active fraction of LBP in antitumor activity.

Apoptosis and cell-cycle arrest are both mechanisms for cytotoxic anticancer drugs work in cancer treatment $[31,32]$. Previous studies had shown that LBP could induce cancer cell apoptosis and cell-cycle arrest [1-5]. In our study, we found that LBP3 disrupted MMP and induced $\mathrm{H} 22$ cell apoptosis. The mitochondrion is the powerhouse of the cell [22], and we conclude that LBP-3 induced H22 cell apoptosis partly by disrupting MMP. Furthermore, LBP- 3 could cause H22 cell arrest at the S phase. This agrees with several previous reports that LBP caused S phase arrest in human hepatoma QGY7703 cells [1] and gastric cancer SGC-7901 cells [3]. However, the other studies showed that LBP caused G0/G1 phase arrest in gastric cancer MGC-803 cells [3] and colon cancer cells [2]. These indicate that multiple mechanisms may be responsible for the anticancer effects of LBP in different types of cancer cells [2].

It is known that cytotoxic chemotherapy drugs not only kill cancer cells but also kill normal cells, which causes toxic side effects [33]. Myelosuppression and immunosuppression are common side effects for most chemotherapy drugs. Since the immune system plays an important role in preventing pathogen invasion, immunosuppression often leads to the development of opportunist infections, and even significant morbidity and mortality [30]. In our study, we found that none of the LBP fractions were cytotoxic to splenocytes, and furthermore LBP3, LBP4, and LBP5 could improve cell viability. In accordance with the in vitro study, none of the LBP fractions suppressed the thymus or spleen index in H22-tumor-bearing mice. In fact, LBP is extracted from the edible Chinese herb, Lycium barbarum. Previous studies have shown that LBP could enhance the proliferation of splenocytes in mice [34,35], activate macrophages [36], and promote both the phenotypic and functional maturation of DC [37]. Besides, LBP also has various other biological activities, such as neuroprotective effects [38,39], radioprotective activity [40], cardioprotective activity [41], and hepatoprotective effects $[42,43]$. Clinical trials have shown that LBP had remarkable protective effects in patients with type 2 diabetes [44]. These indicate that LBP-3 might be safe for cancer treatment. In order to support our conclusion, we further investigated the effect of LBP-3 on liver and kidney in H22-tumor-bearing mice. Results showed that LBP-3 did not cause damage in either liver or kidney tissue (Figure S1 in the supplemental file). Meanwhile, we found that LBP-3 did not cause the serum levels of AST, ALT or BUN increase (Table S1 in the supplemental file) which often indicates the dysfunction of liver and kidney, respectively. Taken together, we conclude that LBP-3 may be safe for antitumor therapy.

\section{Conclusions}

In the present study, the MW-antitumor activity relationship of LBP was investigated both in vitro 
and in vivo. In summary, four water-soluble LBP fractions (LBP-2, LBP-3, LBP-4, and LBP-5) with serial different MWs were separated from LBP by ultrafiltration membranes. In vitro, LBP-3 had the highest inhibition activity on $\mathrm{H} 22$ cells among the four fractions. LBP-3 induced apoptosis, MMP destruction, and $\mathrm{S}$ phase arrest in $\mathrm{H} 22$ cells, but it did not inhibit the cell viability of murine splenocytes. Consistent with the results in vitro, LBP-3 had the highest activity in inhibiting tumor growth and did not suppress the thymus and spleen index in H22-tumor-bearing mice. These results demonstrated that the antitumor activity of LBP was closely related to its MW. LBP-3 with medium MW was the main active fraction of LBP in antitumor therapy, and it seemed to be safe for use in antitumor therapy.

\section{Acknowledgments}

This study was supported by the Specialized Research Fund for the Doctoral Program of Higher Education [Grant No. 20124425110010]; The Special Funds from Central Finance of China in Support of the Development of Local Colleges and University [Educational finance Grant No. 276 (2014)]; and the project funded by the China Postdoctoral Science Foundation [Grant No. 2016M602548]. We also thank Prof. Xiao-Jun Zhang and Yang Chen for critical reading of the manuscript.

\section{Disclosure statement}

No potential conflict of interest was reported by the authors.

\section{Funding}

This work was supported by the China Postdoctoral Science Foundation [2016M602548]; Specialized Research Fund for the Doctoral Program of Higher Education [20124425110010]; The Special Funds from Central Finance of China in Support of the Development of Local Colleges and University [276 (2014)].

\section{References}

[1] Zhang M, Chen H, Huang J, et al. Effect of lycium barbarum polysaccharide on human hepatoma QGY7703 cells: inhibition of proliferation and induction of apoptosis. Life Sci. 2005;76:2115-2124.

[2] Mao F, Xiao B, Jiang Z, et al. Anticancer effect of lycium barbarum, polysaccharides on colon cancer cells involves G0/G1 phase arrest. Med Oncol. 2011;28:121126.

[3] Miao Y, Xiao B, Jiang Z, et al. Growth inhibition and cell-cycle arrest of human gastric cancer cells by lycium barbarum polysaccharide. Med Oncol. 2010;27:785-790.

[4] Gan L, Hua ZS, Liang YX, et al. Immunomodulation and antitumor activity by a polysaccharide-protein complex from lycium barbarum. Int Immunopharmacol. 2014;4:563-569.

[5] Zhang MH, Wang XY, Wang XM, et al. Inhibition of Lycium barbarumpolysaccharide on transplanted liver cancer in mice. Chin Tradit Herbal Drugs. 2012;43:1142-1146.

[6] Qian Z, Lv X, Tao W, et al. Composition oflycium barbarumpolysaccharides and their apoptosis-inducing effect on human hepatoma SMMC-7721 cells. Food Nutr Res. 2015;59:28696.

[7] Jin M, Huang Q, Zhao K, et al. Biological activities and potential health benefit effects of polysaccharides isolated from lycium barbarum L. Int J Biol Macromol. 2013;54:16-23.

[8] Zhang M, Tang X, Wang F, et al. Characterization of lycium barbarum polysaccharide and its effect on human hepatoma cells. Int J Biol Macromol. 2013;61:270-275.

[9] Li W, Li Y, Wang Q, et al. Crude extracts from lycium barbarum suppress srebp-1c expression and prevent diet-induced fatty liver through ampk activation. Biomed Res Int. 2014. DOI:10.1155/2014/196198.

[10] Dubois M, Gilles KA, Hamilton JK, et al. Colorimetric method for determination of sugars and related substances. Anal Chem. 1955;28:350-356.

[11] Bradford MM. A rapid and sensitive method for the quantitation of protein utilizing the principle of protein-dye binding. Anal Biochem. 1976;72:248-254.

[12] Bitter T, Muir H. A modified uronic acid carbazole reaction. Anal Biochem. 1962;4:330-334.

[13] Li HS, Sun MN, Xu J, et al. Immunological response in h22 transplanted mice undergoing aconitum coreanum, polysaccharide treatment. Int $\mathrm{J}$ Biol Macromol. 2013;55:295-300.

[14] Luo X, Zheng YY, Wen RY, et al. Effects of ceftriaxone induced intestinal dysbacteriosis on lymphocytes in different tissues in mice. Immunobiology. 2016;221:994-1000.

[15] J Y S, Luo X, Zhang XJ, et al. Immunosuppressive activity of pogostone on $\mathrm{T}$ cells: blocking proliferation via $S$ phase arrest. Int Immunopharmacol. 2015;26:328337.

[16] Yang B, Xiao B, Sun T. Antitumor and immunomodulatory activity of astragalus membranaceus, polysaccharides in h22 tumor-bearing mice. Int J Biol Macromol. 2013;62:287-290.

[17] Sun Y, Liu J, Yue L, et al. One proteoglycan from the fruiting bodies of chroogomphis rutilus (schaeff.: fr.) o. k. miller: purification and structural features. Carbohydr Polym. 2011;86:1381-1384.

[18] Liang B, Jin M, Liu H. Water-soluble polysaccharide from dried Lycium barbarum fruits: isolation, structural features and antioxidant activity. Carbohydr Polym. 2011;83:1947-1951.

[19] Sheng X, Yan J, Meng Y, et al. Immunomodulatory effects of Hericium erinaceus derived polysaccharides are mediated by intestinal immunology. Food Funct. 2017;8:1020-1027.

[20] Chen Z, Kwong HTB, Chan SH. Activation of T lymphocytes by polysaccharide-protein complex from Lycium barbarum L. Int Immunopharmacol. 2008;8:1663-1671.

[21] Vermes I, Haanen C, Steffens-Nakken H, et al. A novel assay for apoptosis Flow cytometric detection of 
phosphatidylserine expression on early apoptotic cells using fluorescein labeled Annexin V. J Immunol Methods. 1995;184:39-51.

[22] Picard M, Wallace DC, Burelle Y. The rise of mitochondria in medicine. Mitochondrion. 2016;30:105-116.

[23] Fang SQ, Wang YT, Wei JX, et al. Beneficial effects of chlorogenic acid on alcohol-induced damage in PC12 cells. Biomed Pharmacother. 2016;79:254-262.

[24] Giannattasio S, Guaragnella N, Arbini AA, et al. Stressrelated mitochondrial components and mitochondrial genome as targets of anticancer therapy. Chem Biol Drug Des. 2013;81:102-112.

[25] Dai JQ, Huang YG, He AN. Dihydromethysticin kavalactone induces apoptosis in osteosarcoma cells through modulation of PI3K/Akt pathway, disruption of mitochondrial membrane potential and inducing cell cycle arrest. Int J Clin Exp Patho. 2015;8:4356-4366.

[26] Berenbaum MC. Immunosuppression by platinum diamines. Brit J Cancer. 1971;25:208-211.

[27] Sánchezsuárez P, Ostroskywegman P, Gallegoshernández F, et al. DNA damage in peripheral blood lymphocytes in patients during combined chemotherapy for breast cancer. Mutat Res-Fund Mol M. 2008;640(1-2):8-15.

[28] Harris J, Sengar D, Stewart T, et al. The effect of immunosuppressive chemotherapy on immune function in patients with malignant disease. Cancer. 1976;37:1058-1069.

[29] Ozolins TR. Cyclophosphamide and the teratology society: an awkward marriage. Birth Defects Res B Dev Reprod Toxicol. 2010;89:289-299.

[30] Becker MS, Schmezer P, Breuer R, et al. The traditional Chinese medical compound Rocaglamide protects nonmalignant primary cells from DNA damage-induced toxicity by inhibition of p53 expression. Cell Death Dis. 2014;5:e1000.

[31] Hunter AM, Lacasse EC, Korneluk RG. The inhibitors of apoptosis (IAPs) as cancer targets. Apoptosis. 2007;12:1543-1568.

[32] Visconti R, Monica RD, Grieco D. Cell cycle checkpoint in cancer: a therapeutically targetable double-edged sword. J Exp Clin Cancer Res. 2016;35:153-doi.

[33] Levesque JP, Winkler IG. It takes nerves to recover from chemotherapy. Nat Med. 2013;19:669-671.
[34] Bo R, Sun Y, Zhou S, et al. Simple nanoliposomes encapsulating Lycium barbarum polysaccharides as adjuvants improve humoral and cellular immunity in mice. Int J Nanomed. 2017;173:6289-6301.

[35] Peng XM, Huang LJ, Qi CH, et al. Studies on chemistry and immuno-modulating mechanism of a glycoconjugate from Lycium barbarum L. Chin J Chem. 2010;19:1190-1197.

[36] Zhang XR, Qi CH, Cheng JP, et al. Lycium barbarum polysaccharide LBPF4-OL may be a new Toll-like receptor 4/MD2-MAPK signaling pathway activator and inducer. Int Immunopharmacol. 2014;19:132-141.

[37] Zhu J, Zhao LH, Zhao XP, et al. Lycium barbarum polysaccharides regulate phenotypic and functional maturation of murine dendritic cells. Cell Biol Int. 2007;31:615-619.

[38] Ho YS, Yu MS, Yik SY, et al. Polysaccharides from wolfberry antagonizes glutamate excitotoxicity in rat cortical neurons. Cell Mol Neurobiol. 2009;29:12331244.

[39] Teng P, Li Y, Cheng W, et al. Neuroprotective effects of Lycium barbarum polysaccharides in lipopolysaccharide-induced BV2 microglial cells. Mol Med Rep. 2013;7:1977-1981.

[40] Gong H, Shen P, Jin L, et al. Therapeutic effects of Lycium barbarum polysaccharide (LBP) on irradiation or chemotherapy-induced myelosuppressive mice. Chin J Inf Tradit Chin Med. 2005;20:155-162.

[41] Xin YF, Wan LL, Peng JL, et al. Alleviation of the acute doxorubicin-induced cardiotoxicity by Lycium barbarum polysaccharides through the suppression of oxidative stress [J]. Food Chem Toxicol. 2011;49:259-264.

[42] Xiao J, Liong EC, Ching YP, et al. Lycium barbarum polysaccharides protect rat liver from non-alcoholic steatohepatitis-induced injury. Nutr Diabetes. 2013;3:e81.

[43] Jia L, Li W, Li J, et al. Lycium barbarum polysaccharide attenuates high-fat diet-induced hepatic steatosis by upregulating SIRT1 expression and deacetylase activity. Sci Rep. 2016;6:36209-doi. DOI:10.1038/srep36209.

[44] Cai H, Liu F, Zuo P, et al. Practical application of antidiabetic efficacy of lycium barbarum polysaccharide in patients with type 2 diabetes. Med Chem. 2015;11:383-390. 